\title{
Efeito da ovitrampa letal na longevidade de fêmeas de Aedes aegypti (Diptera: Culicidae)
}

\author{
Effect of lethal ovitrap on the longevity of females of \\ Aedes aegypti (Diptera: Culicidae)
}

\author{
Renata Antonaci Gama ${ }^{1}$, Álvaro Eduardo Eiras ${ }^{1}$ \\ e Marcelo Carvalho de Resende ${ }^{1}$
}

\begin{abstract}
RESUMO
A armadilha de oviposição acrescida de inseticida pode funcionar como novo método de controle de fêmeas do mosquito Aedes aegypti. Fêmeas de Aedes aegypti foram colocadas em contato com ovitrampas letais envelhecidas e a mortalidade variou de 60,3\% a 100\% sendo significativo o efeito do envelhecimento das palhetas impregnadas com deltametrina no percentual de mortalidade..
\end{abstract}

Palavras-chaves: Aedes aegypti. Controle. Ovitrampa letal.

\section{ABSTRACT}

Oviposition traps with added insecticide may work as a new method for controlling the females of the Aedes aegypti mosquito. Females of Aedes aegypti were placed in contact with lethal ovitraps with aging. The mortality rate ranged from $60.3 \%$ to $100 \%$. The effect of aging the slats impregnated with deltamethrin was significant in relation to the percentage mortality among Aedes aegypti females.

Key-words: Aedes aegypti. Control. Lethal ovitrap.

O Aedes aegypti é um mosquito predominantemente doméstico, que se caracteriza por reproduzir-se em recipientes artificiais nas habitações humanas e aos arredores destas 5 .

A ovitrampa (armadilha de oviposição) foi desenvolvida inicialmente como uma ferramenta de vigilância deAedes aegypti nos Estados Unidos e vem sendo implementada em diversos programas de monitoramento, funcionando como método indireto para avaliar a presença desse vetor ${ }^{2}$. A adição de infusão de gramíneas nas ovitrampas funciona como atraente ${ }^{3} \mathrm{e}$ tem demonstrado aumentar a oviposição.

Modificações no substrato de postura de ovos dos mosquitos nas armadilhas de oviposição pela substituição da palheta de madeira prensada por uma tira de papel impregnada com inseticida permitiu o desenvolvimento de um novo método de controle para fêmeas de Aedes aegypti denominado ovitrampa letal ${ }^{6}$.

0 presente trabalho teve como objetivo avaliar o efeito do contato das fêmeas de Aedes aegypti com as armadilhas de oviposição letais e a persistência em condições simuladas de campo para o inseticida deltametrina impregnado na concentração de $1 \mathrm{mg}$ ingrediente ativo por palheta.

\section{MATERIAL E MÉTODOS}

Mosquitos. Fêmeas de Aedes aegypti cepa Rockefeller mantidas em condições de laboratório com temperatura de $25^{\circ} \mathrm{C} \pm 2^{\circ} \mathrm{C}$, umidade relativa $65 \% \pm 10 \%$ e fotoperíodo de 12 horas sem exposição a inseticida e suscetíveis a inseticidas piretróides foram utilizadas nos testes.

Fermentação de gramíneas. Quarenta e dois gramas de capim colonião (Panicum maximum) foram colocados em um galão contendo cinco litros de água e mantido a $25^{\circ} \mathrm{C}$ durante sete dias . Após esse período de fermentação, a infusão foi diluída a $10 \%$ para adição nas armadilhas de oviposição.

Preparação das armadilhas. A ovitrampa letal é composta de um frasco de plástico de cor preta com volume de $473 \mathrm{ml} \mathrm{com}$ adição da infusão de gramínea à 10\% e uma palheta de papel como substrato de oviposição impregnada com 1mg i.a./palheta do inseticida deltametrina.

Realização do teste. Cinqüienta ovitrampas, sendo 25 com e 25 sem inseticida, foram colocadas em condições de semicampo

\footnotetext{
1. Laboratório de Ecologia Química de Insetos Vetores, Departamento de Parasitologia, Universidade Federal de Minas Gerais, Belo Horizonte, MG Apoio financeiro: Conselho Nacional de Desenvolvimento Científico e Tecnológico (CNPq)

Endereço para correspondência: Dr. Marcelo de Carvalho Resende. Rua Rio de Janeiro 1200, Centro, 30160-041 Belo Horizonte, MG.

Telefax: $55313222-6707$

e-mail: resendemarcelo@ig.com.br

Recebido para publicação em: 25/08/2007

Aceito em: 11/10/2007
} 
por 60 dias e, durante este tempo, 10 (cinco tratamento e cinco controle) eram retiradas em intervalos de 1, 15, 30, 45 e 60 dias. As armadilhas foram colocadas em gaiolas de acrílico (40x 40x $40 \mathrm{~cm}$ ) contendo 50 fêmeas de Aedes aegypti alimentadas com sangue. Diariamente observou-se a mortalidade e os mosquitos mortos eram retirados com a ajuda de um papel de filtro e um sugador manual. A alimentação açucarada à $10 \%$ foi provida durante todo o período de exposição e trocada a cada dois dias e a leitura de mortalidade observada nas gaiolas de exposição e controle foram realizadas por um período de sete dias.

Análise estatística. A taxa de mortalidade foi calculada para cada tratamento em diferentes tempos de envelhecimento da palheta impregnada com deltametrina (1, 15, 30, 45 e 60 dias). Pela análise de variância foi analisada a mortalidade das fêmeas de Aedes aegypti após o contato com a ovitrampa letal, seguido de teste Tukey (Sokal e Rolf 1995). Todas as análises estatísticas foram realizadas no programa Systat V.8.0.

\section{RESULTADOS}

A mortalidade observada das fêmeas de Aedes aegypti expostas as armadilhas letais, durante 7 dias com 1, 15, 30, 45 e 60 dias de envelhecimento, foi de $100 ; 97,7 ; 70,5 ; 77,7$ e $60,3 \%$ respectivamente (Tabela 1 ). Observou-se uma redução significativa $(\mathrm{F}=155,8 ; \mathrm{p}<0,01)$ na mortalidade das fêmeas de Aedes aegypti ao final da exposição de sete dias com o aumento no tempo de envelhecimento das armadilhas letais no campo.

\begin{tabular}{|c|c|c|c|}
\hline Tratamento (dias) & $\begin{array}{c}\text { Total de fêmeas } \\
\text { expostas }\end{array}$ & $\begin{array}{l}\text { Total de fêmeas } \\
\text { mortas }\end{array}$ & $\begin{array}{c}\text { Mortalidade } \\
\text { observada (\%) }\end{array}$ \\
\hline 1 & 250 & 250 & $100,0 \mathrm{a}$ \\
\hline 15 & 250 & 245 & $97,7 \mathrm{a}$ \\
\hline 30 & 250 & 183 & $70,5 \mathrm{c}$ \\
\hline 45 & 250 & 204 & $77,7 \mathrm{~b}$ \\
\hline 60 & 250 & 161 & $60,3 \mathrm{~d}$ \\
\hline
\end{tabular}

As médias seguidas pela mesma letra não apresentam diferença significativa (Tukey $\mathrm{p}<0,05)$. A mortalidade observada já está corrigida pela fórmula de Abbott.

Em observações diárias da mortalidade das fêmeas de Aedes aegypti em condições de laboratório verificou-se que nas primeiras 72 horas de exposição ocorreu a maior mortalidade para os tempos de envelhecimento de 1 dia (100\%), 15 dias $(86,1 \%), 30$ dias $(54 \%)$ e 45 dias $(61,3 \%)$, exceto para 60 dias $(31,9 \%)$ de envelhecimento que apresentou um padrão de mortalidade média diária de fêmeas de Aedes aegypti similar durante os sete dias de avaliação (Figura 1). Observa-se que a mortalidade diária dos insetos adultos variou de acordo com o tempo de envelhecimento da palheta, concordando com os dados de mortalidade observada final onde as palhetas com idades de envelhecimento inferior a 45 dias apresentaram uma performance de controle acima de $70 \%$ dos insetos expostos.

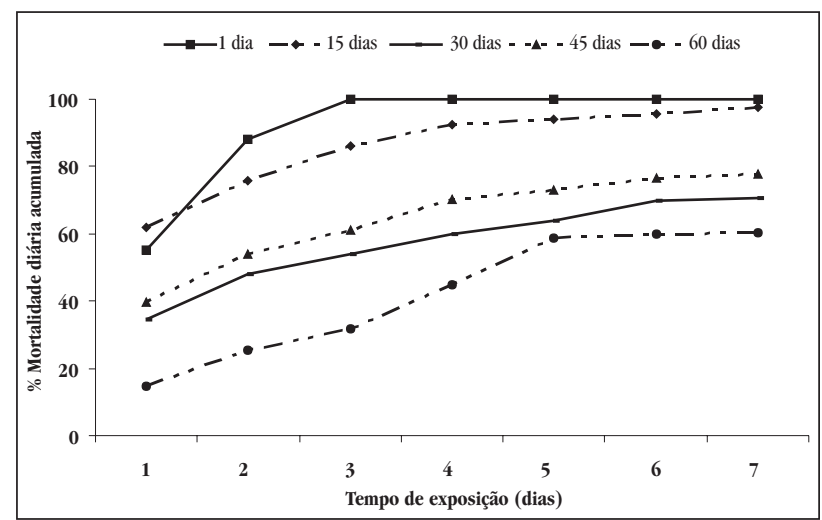

Figura 1 - Percentual de mortalidade diária das fêmeas de Aedes aegypti expostas durante 7 dias a palbetas impregnadas com $1 \mathrm{mg}$ deltametrina e envelhecidas 1,15,30,45 e 60 dias.

\section{DISCUSSÃ0}

O Programa Nacional de Controle da Dengue/Ministério da Saúde do Brasil tem como normas técnicas de controle ao mosquito Aedes aegypti o uso de inseticidas organofosforados e bactérias entomopatogênicas para as formas imaturas e inseticidas piretróides para as formas aladas ${ }^{1}$. A utilização de armadilhas de oviposição com palhetas impregnadas com 1mg i.a./palheta de deltametrina para o controle desse vetor seria uma metodologia alternativa como parte de uma estratégia de controle integrado de vetores. A utilização das armadilhas de oviposição associada com atraentes melhora a especificidade e sensibilidade, contribuindo no controle exercido pela armadilha letal. Na palheta impregnada com inseticida, ocorre o contato do inseto adulto e a postura de ovos de Aedes aegypti e se estes eclodem, dados de laboratório demonstraram que as larvas em contato com água da palheta impregnada com inseticida morrem nos estágios iniciais de desenvolvimento (RA Gama, MC Resende: dados não publicados), o que viabiliza a permanência dessa armadilha em campo por um período maior sem que a mesma se torne um criadouro do vetor alvo.

Zeichner $^{6}$ ao testar a ovitrampa letal em laboratório obteve resultados semelhantes ao presente trabalho. Foi observada uma mortalidade de 94\% das fêmeas de Aedes aegypti $(\mathrm{n}=366)$ expostas por $48 \mathrm{~h}$ às armadilhas de oviposição contendo 0 inseticida deltametrina e infusão. Perich ${ }^{7}$ ao realizar ensaios em campo nos municípios de Areia Branca e Nilópolis (RJ) com a ovitrampa letal, durante três meses (março a maio) em 2001, observou uma redução da população de mosquitos através da aspiração de adultos, média de pupas por casa e Índice de Recipiente e, indica a utilização da armadilha letal no controle de Aedes aegypti em associação com a participação comunitária como medidas eficientes para o controle da dengue.

Os resultados dos testes simulados de campo com as palhetas impregnadas com deltametrina indicam que as mesmas sejam trocadas preferencialmente a cada 45 dias de envelhecimento onde se observou taxa de mortalidade superior a $70 \%$ das fêmeas de Aedes aegypti. 


\section{AGRADECIMENTOS}

Ao Conselho Nacional de Desenvolvimento Científico e Tecnológico $(\mathrm{CNPq})$ pela bolsa de pesquisa, Aos funcionários Giovani Pontel Gonçalves e Suzana MB. Rebouças do Núcleo de Entomologia da FUNASA e ao Dr. Michael J.Perich (In memorian) do Walter Reed Army Institute, Washington D.C, USA.

\section{REFERÊNCIAS}

1. Fundação Nacional de Saúde. Treinamento de monitores quanto às medidas de segurança química. Ministério da Saúde. Brasília, 1999.

2. Nelson JM. Aedes aegypti: Biologia y Ecologia. Organizacion Panamericana de la Salud.Washington, DC. 1986
3. Perich MJ, Kardec A, Braga IA, Portal F, Burge R, Zeichner BC, Brogdon WA, Wirtz RA. Field evaluation of a lethal ovitrap against dengue vectors in Brazil. Medical and Veterinary Entomology 17: 205-210, 2003.

4. Reiter P, Amador MA, Colon N. Enhancemente of the CDC ovitrap whit hay infusions for daily monitoring of Aedes aegypti populations. Journal of the Americam Mosquito Control Association 7: 52-55, 1991.

5. Roque RA. Avaliação de armadilhas iscadas com infusão de gramíneas como ataentes e/ ou estimulantes de oviposição do Mosquito Aedes (Stegomyia) sp. (Diptera: Culicidae). Dissertação de Mestrado, Universidade Federal de Minas Gerais, Belo Horizonte, MG, 2002.

6. Superintendência de Controle de Endemias. Biologia y Control delAedes aegypti. Vector Tropics 4: 22-28,1980.

7. Zeichner BC, Perich MJ. Laboratory testing of a lethal ovitrap for Aedes aegypti. Medical and Veterinary Entomology 13: 234-238, 1999. 